$\mathbf{R}_{\text {ESEARCh }} \mathbf{P}_{\text {APER }} \longrightarrow \frac{\text { FOOD SCIENCE }}{\text { RESEARCH JOURNAL }}$

\title{
Assessment of nutrients intake of Christian pastor and Christian community
}

\author{
Amrita Masih and Vinita Singh
}

\begin{abstract}
Christian pastors and Christian community has the special dietary requirements of the food choices and balanced diet to maintain a healthy lifestyle and to promote longevity, there are various obstacles that prevent or limit from practicing and benefiting from good eating habits. Total of hundred respondents age between (20 to 50 above) were selected from Nutritional Assessment of Christian pastor and Christian community of Churches in Kanpur City ( 52 males, 48 females). Data on socio-demographic information dietary habits, physical activities, morbidity patterns, personal and social adjustments and prevalence of non-communicable diseases were recorded using a pretested schedules/ questionnaire), diet of each respondent was recorded by using the 24 hours dietary recall method and nutrient intake was calculated .The optimal health can be achieved from a diet that emphasizes a generous intake of vegetables and fruits such plant enriched diets can be not only healthy but interesting and enjoyable as well. The maximum 43.24 per cent deficiency of energy was found in 20-30 years of age group, and 37.44 per cent deficiency of energy was found in 40-50 years of age group. 36.11 per cent deficiency of energy was found in 50 years and above age group. The maximum 32.84 per cent deficiency of protein was found in 40-50 years of age group and 29.91 per cent deficiency of protein was found in 50 and above years of age group. 26.15 per cent deficiency of protein was found in 20-30 years of age group. The maximum 17.80 per cent deficiency of fat was found in 40-50 years of age group and 16.44 per cent deficiency of fat was found in 20-50 years of age group. 14.4 per cent deficiency of fat was found in 50years and above age group. The maximum 25.49 per cent deficiency of calcium was found in 40-50 years of age group and 25.13 per cent deficiency of calcium was found in 50 years above of age group. 24.22 per cent deficiency of calcium was found in 20-30 years of age group. The maximum 15.30 per cent deficiency of iron was found in 20-30 years of age group, and 5.33 per cent deficiency of iron was found in 40-50 years of age group. 5.33 per cent deficiency of iron was found in 50 years and above age group. The maximum 15.97 per cent deficiency of vitamin A was found in 40-50 years of age group, and 15.92 per cent deficiency of vitamin A was found in 20-30 years of age group. 14.76 per cent deficiency of vitamin A was found in 50 years and above age group.
\end{abstract}

Key Words : Assessment, Christian pastor, Christian community, Intake, Nutrients

How to cite this article : Masih, Amrita and Singh, Vinita (2017). Assessment of nutrients intake of Christian pastor and Christian community. Food Sci. Res. J., 8(1): 119-122, DOI : 10.15740/HAS/FSRJ/8.1/119-122.

Author for correspondence :

AMRITA MASIH, Department of Food Science and Nutrition, C.S.A. University

of Agriculture and Technology, KANPUR (U.P.) INDIA

Email : amritamasih1494@gamil.com

Associate Authors' :

VINITA SINGH, Department of Food Science and Nutrition, C.S.A. University

of Agriculture and Technology, KANPUR (U.P.) INDIA

Email : svinita2008@gmail.com 